\title{
Does the cellular bronchoalveolar lavage fluid profile reflect the severity of sarcoidosis?
}

\author{
M. Drent*, J.A. Jacobs ${ }^{+}$, J. de Vries ${ }^{\#}$, R.J.S. Lamers ${ }^{\star}$ I.H. Liem ${ }^{\S}$, E.F.M. Wouters*
}

\begin{abstract}
Does the cellular bronchoalveolar lavage fluid profile reflect the severity of sarcoidosis? M. Drent, J.A. Jacobs, J. de Vries, R.J.S. Lamers, I.H. Liem, E.F.M. Wouters. (C)ERS Journals Ltd 1999.

ABSTRACT: The aim of this study was to assess whether the cellular bronchoalveolar lavage fluid (BALF) profile, particularly the number of polymorphonuclear neutrophils (PMNs), is associated with disease severity of sarcoidosis and its usefulness in determining remission.

Twenty-six nonsmoking outpatients with sarcoidosis were included in this study. The patients were divided into two subgroups according to the absolute number of PMNs in BALF: $\leq 0.2 \times 10^{4}$ cells $\cdot \mathrm{mL}^{-1}$ (group $1 ; \mathrm{n}=15$ ) and $>0.2 \times 10^{4}$ cells $^{-\mathrm{mL}^{-1}}$ (group 2; $\mathbf{n}=11$ ).

The radiographic stage, high-resolution computed tomography (HRCT) findings, ${ }^{67} \mathrm{Ga}$ lung uptake as well as lung function tests differed significantly between group 1 and 2. Follow-up revealed that $14(93.3 \%)$ patients of group 1 compared to four (36.4\%) of group 2 recovered spontaneously without the help of corticosteroids. In contrast, no differences were found in the number of lymphocytes in BALF nor in the serum angiotensin converting enzyme (sACE) level between both groups. The number of PMNs, the transfer factor of the lungs for carbon monoxide $(T \mathrm{~L}, \mathrm{CO})$, the forced expiratory volume in one second (FEV1) and one of the HRCT subscores discriminated between patients with different disease progression. Of these parameters the PMNs appeared to be the only one which differentiated patients who demonstrated remission and those who deteriorated.

In conclusion, these results indicate that the number of polymorphonuclear neutrophils in bronchoalveolar lavage fluid distinguish between sarcoidosis patients who demonstrated remission and those having a more severe course of the disease. Whether polymorphonuclear neutrophils may be considered as markers of disease activity and/or prognosis in sarcoidosis needs further investigation. Eur Respir J 1999; 13: 1338-1344.
\end{abstract}

Depts of *Pulmonology, ${ }^{+}$Medical Microbiology, ${ }^{*}$ Radiology, and ${ }^{\S}$ Nuclear Medicine, University Hospital Maastricht, the Netherlands. "Dept of Research Technology, Tilburg University, the Netherlands.

\section{Correspondence: M. Drent}

University Hospital Maastricht

Dept of Pulmonology

PO Box 5800

6202 AZ Maastricht

The Netherlands

Fax: 31433875051

Keywords: Bronchoalveolar lavage

inflammation

neutrophils

prognosis

sarcoidosis

treatment

Received: June 301998

Accepted after revision March 71999
Sarcoidosis is a multisystemic disease of unknown origin, characterized by the formation of noncaseating epitheloid cell granulomas, probably antigen driven, and derangement of normal tissue architecture [1-3]. Granuloma formation in the lung is preceded by a mononuclear cell alveolitis with increased numbers of activated T-lymphocytes and alveolar macrophages [1-6]. Studies employing bronchoalveolar lavage fluid (BALF) have resulted in major advances in the understanding of the pathogenesis of many pulmonary diseases. Furthermore, bronchoalveolar lavage (BAL) has the potential to be useful for assessment of disease activity, prognosis and in guiding therapy. In other interstitial lung disorders with various, rather uncertain, prognoses, such as idiopathic pulmonary fibrosis (IPF), a marked increase in polymorphonuclear neutrophils (PMNs) and/or eosinophils was reported to adversely affect prognosis, whereas elevated lymphocyte counts were found to be more likely to be associated with a good response to corticosteroid treatment $[7,8]$. However, until now, there has been no consensus about the relation of the cellular composition of BALF with clinical features and the results of other diagnostic procedures in a given individual sarcoidosis patient. Moreover, BALF analysis results possess limited prognostic value. Thus, this is the most critically discussed issue in the field of BAL, which needs to be clarified.

The aim of the present study was to investigate whether the BALF cellular profile, particularly the number of PMNs, is associated with: 1) disease severity reflected by clinical features, 2) the results of other diagnostic procedures, and 3) its usefulness in determining whether treatment is required or spontaneous remission is anticipated in sarcoidosis. As smoking has been found to adversely affect the alveolar inflammation, only nonsmoking patients suffering from sarcoidosis and control subjects were evaluated.

\section{Material and methods}

\section{Subjects}

Twenty-six nonsmoking outpatients with newly suspected sarcoidosis (11 females, 15 males; aged 40.8 \pm 11.9 yrs $($ mean \pm SD $)$ ) were included in this study. The diagnosis of sarcoidosis was based on consistent clinical features, together with BALF analysis results [9]. Moreover, all 
patients had a biopsy confirmation of sarcoidosis. The clinical symptoms of the respective patients varied from none (sarcoidosis detected on routine chest radiography) to more or less severe respiratory symptoms or erythema nodosum and arthralgia (i.e. Lofgren's syndrome). None of the subjects participating had any significant medical history or comorbidity. No patient had taken corticosteroids prior to when the BAL was performed. Moreover, cultures of the BALF samples obtained were all negative. In the course of the initial diagnosis, serological parameters including serum angiotensin converting enzyme (sACE) and C-reactive protein (CRP) were assessed.

To be informed about the presence of constitutional symptoms, the patients participating completed a symptom questionnaire [10] under supervision of a study assistant, to ensure correct answers and to avoid omission of data. The control group consisted of 11 nonsmoking healthy volunteers (never smokers; zero pack-yrs), without any pulmonary history, having normal chest radiography and lung function tests. Written informed consent was obtained from all participating subjects.

\section{Bronchoalveolar lavage}

BAL was performed as previously reported during fibreoptic bronchoscopy [9]. In brief, after premedication (atropine and sometimes diazepam) and local anaesthesia of the larynx and bronchial tree (lidocaine $0.5 \%$ ), BAL was performed by standardized washing of the middle lobe with four aliquots of $50 \mathrm{~mL}$ sterile saline $(0.9 \%$ $\mathrm{NaCl})$ at $37^{\circ} \mathrm{C}$. After careful mixing the BALF recovered was split into two portions, kept on ice in a siliconized specimen trap. Portion one was separated from cellular compounds by centrifugation (for $5 \mathrm{~min}$ at $350 \times g$ ). After an additional centrifugation step (for $10 \mathrm{~min}$ at $1,000 \times \mathrm{g}$ ) supernatants were directly stored at $-70^{\circ} \mathrm{C}$. The cells were washed twice, counted and suspended in minimal essential medium (MEM; Gibco, Grand Island, NY, USA) supplemented with $1 \%$ bovine serum albumin (BSA; Organon, Teknika, Boxtel, the Netherlands). Preparations of the cell suspensions were made in a cytocentrifuge (Cytospin 3, Shandon Scientific Ltd., Astmoor, UK). Cytospin slides of BAL cells were stained with MayGrünwald-Giemsa (MGG; Merck, Darmstadt, Germany) for cell differentiation. At least 500 cells were counted.

\section{Lung function and respiratory muscle strength}

Lung function measurements included forced expiratory volume in one second (FEV1), and inspiratory vital capacity (IVC) measured with a pneumotachograph (Masterlab, Jaeger, Würzburg, Germany). The transfer factor of the lung for carbon monoxide $(T \mathrm{~L}, \mathrm{CO})$ was measured by the single-breath method. Values were expressed as a percentage of those predicted [11].

Inspiratory and expiratory muscle strength were assessed by measuring maximal respiratory mouth pressures using the method of L.F. Black and R.E. Hyatt as previously reported [12]. Maximal inspiratory mouth pressure $(P \mathrm{I}, \mathrm{max})$ was measured at residual volume (RV), whilst maximal expiratory mouth pressure $(P \mathrm{E}, \mathrm{max})$ was measured at total lung capacity (TLC). The equipment used was a pressure transducer (model MP 45-30; Validyne Engineering Corp., Northridge, CA, USA). All signals were recorded on a strip chart (type BD 31; Kipp \& Zonen, Delft, the Netherlands). Values are expressed as absolute terms and as percentage of predicted values [12].

\section{Chest radiographs}

Chest radiographs were made in the posterior-anterior and lateral projections, and were classified by a single experienced reader, blinded to the patients' clinical history, in a standard manner according to the radiographic stage $(0-\mathrm{IV})$.

\section{$H R C T$}

Thin section scans with $1 \mathrm{~mm}$ collimation were obtained at $10-\mathrm{mm}$ intervals through the chest. The scanning parameters included $137 \mathrm{kVp}, 255 \mathrm{~mA}$, and 1-s scanning time. Both mediastinal (width $400 \mathrm{HU}$; level $40 \mathrm{HU}$ ) and lung (width 1,600 HU; level -800 HU) window images were obtained. Scans were reconstructed with a high-frequency reconstruction algorithm. A single experienced reader, blinded to the patient's clinical history, classified the scans. The typical patterns of parenchymal involvement were qualitatively registered as thickening or irregularity of the bronchovascular bundle (BVB), intraparenchymal nodules (ND), septal and nonseptal lines (LS) and parenchymal consolidation (PC; including ground-glass opafication) as well as the volume affected, which was quantified by a visual score: $0=$ no lesions found; $1=\leq 33 \% ; 2=\leq 66 \% ; 3=$ $\geq 66 \%$ of the volume affected. Similarly, the quantification of the focal pleural (PL) thickening with respect to the enlargement of the lymph nodes (LN) was performed: $0=$ no pathological findings, $1=$ minor, $2=$ moderate, and $3=$ pronounced changes [13].

\section{Gailium-67 scintigraphy}

To objectify the extent of sarcoidosis, ${ }^{67} \mathrm{Ga}$ scintigraphy was performed. Planar images were obtained 48 and $96 \mathrm{~h}$ after intravenous injection of $148 \mathrm{MBq}(4 \mathrm{MCi})$ of ${ }^{67} \mathrm{Ga}$ citrate, using a dual head gamma camera (Siemens Multispect II, Hoffman estates, IL, USA) with medium energy collimators [14]. A single experienced reader, blinded to the patient's clinical history, classified the scintigrams. Accumulation of ${ }^{67} \mathrm{Ga}$ in the lungs, mediastinum or hilar lymph nodes was considered pathological if the intensity equalled or exceeded liver uptake. Active sarcoidosis outside the thorax was also repeatedly detected, but these findings were not evaluated extensively in this study.

\section{Statistical analysis}

The data of the control subjects and sarcoidosis patient groups were compared using one way analyses of variance (ANOVA) for ordinal values and Chi-squared tests for nominal values. Differences in personal characteristics were assessed using Chi-squared tests for nominal data and Student's t-tests for continuous data. Results are presented 
as mean \pm SD unless stated otherwise. In order to evaluate the remission, one-way ANOVAs were employed. In all tests a $p$-value of $<0.05$ was considered to be statistically significant. All analyses were performed using the Statistical Package for Social Science (SPSS) for Windows (SPSS, Chicago, IL, USA). In addition, Cohen's d (mean difference divided by the pooled standard deviation) was used for effect size. A Cohen's d of $\geq 0.8$ is considered a large effect [15]. A value of $\geq 0.5$ indicates a moderate effect. The higher the Cohen's d-value is, the more relevant the difference between two compared groups is.

\section{Results}

\section{Bronchoalveolar lavage fluid analysis results}

The sarcoidosis patient population $(n=26)$ was divided into two subgroups with respect to the number of PMNs. As none of the control subjects $(n=11)$ nor the control subjects of previous studies $[5,6,9]$ had an absolute number of PMNs in BALF of $>0.2 \times 10^{4}$ cells $\cdot \mathrm{mL}^{-1}$ this value was used as cut-off value. Group $1(n=15)$ consisted of patients with a normal absolute number of PMNs $\left(\leq 0.2 \times 10^{4}\right.$ cells $\left.\cdot \mathrm{mL}^{-1}\right)$ in BALF, and group $2(\mathrm{n}=11)$ consisted of those patients with a high number of PMNs $\left(>0.2 \times 10^{4}\right.$ cells $\left.\cdot \mathrm{mL}^{-1}\right)$. The BALF analysis results of the studied sarcoidosis patients as well as the healthy control group are given in table 1 . The total cell count, the differential cell counts as well as the CD4/CD8 ratio differed significantly between both sarcoidosis subpopulations and the control group. Between group 1 (normal absolute number of PMNs) and group 2 (high number of PMNs) no significant differences were found regarding the other cell types present in BALF (table 1). Microscopic and cytological examination of the BALF samples revealed no acid-fast bacilli, fungi or atypical cells.

\section{Clinical characteristics of the studied sarcoidosis pa- tients}

The clinical characteristics of the sarcoidosis subgroups 1 (normal PMNs) and 2 (high PMNs) are summarized in table 2 . The time between the onset of symptoms and the final diagnosis of sarcoidosis was $0.87 \pm 0.40$ yrs (range 0 -
$6 \mathrm{yrs}$ ) in group 1 and $1.00 \pm 0.54 \mathrm{yrs}$ (range $0-6 \mathrm{yrs}$ ) in group 2, respectively. Of the symptoms associated with extrapulmonary localization of the sarcoidosis only arthralgia differed between both groups (group 1: 66.6\%; group 2: $18.2 \%$; Chi-squared $(\mathrm{l})=5.8, \mathrm{p}<0.02)$. These symptoms were treated with supportive care including physical therapy and sometimes nonsteroidal anti-inflammatory drugs (NSAIDS). No differences were found in the sACE level between group 1 and 2 nor in any other laboratory parameter assessed. The FEV1, FVC and $T \mathrm{~L}, \mathrm{CO}$ (all expressed as percentage of the predicted value) appeared to be lower in the subgroup with a high absolute number of PMNs in BALF (group 2; $<<0.0001$ ) as well as the resting arterial oxygen tension $(\mathrm{p}<0.05)$. The radiographic stage appeared to be high in group 2 compared to group $1(\mathrm{p}<0.001)$ as well as the ${ }^{67} \mathrm{Ga}$ uptake in the lung parenchyma $(\mathrm{p}<0.001)$. Moreover, the HRCT visual scores varied between group 1 and $2(p<0.05$; table 2$)$. None of the studied patients had signs of pleural thickening.

\section{Follow-up of the studied sarcoidosis patients}

The mean follow-up time for group 1 was 16 months (range 10-28 months), and for group 218 months (range 9-34 months). Follow-up of the respiratory symptoms and related clinical features revealed that 14 out of the 15 $(93.3 \%)$ patients of group 1 recovered spontaneously, in contrast to four of the $11(36.4 \%)$ patients of group 2 . These latter four patients were found to have a radiographic stage classification of II. The reason for initiating treatment included the presence of respiratory symptoms, particularly desaturation during exercise. This treatment was started three months (range, 0-6 months) after the initial BAL was performed. Initially, all of the treated patients received corticosteroids. The one treated patient out of group 1 reported no relapse following cessation of corticosteroid therapy for $>1 \mathrm{yr}$.

In two of the seven patients of group 2 who required systemic corticosteroid treatment complete remission was achieved. Two others of the treated patients deteriorated after withdrawal of the corticosteroids. Therefore, the treatment with corticosteroids was restarted and has continued until now (follow-up 18 and 24 months, respectively).

Table 1. - Bronchoalveolar lavage fluid (BALF) characteristics of patients with sarcoidosis and healthy control subjects

\begin{tabular}{|c|c|c|c|c|c|c|}
\hline & \multirow{2}{*}{$\underset{n=15}{\text { Group }} 1$} & \multirow{2}{*}{$\begin{array}{c}\text { Group } 2 \\
n=11\end{array}$} & \multirow{2}{*}{$\begin{array}{c}\text { Group } 3 \\
n=11\end{array}$} & \multicolumn{3}{|c|}{ Cohen's d } \\
\hline & & & & Group 1 vs 2 & Group 1 vs 3 & Group 2 vs 3 \\
\hline Yield \% & $55.4 \pm 3.6^{+}$ & $41.1 \pm 5.2^{\#}$ & $59.6 \pm 3.4$ & 0.31 & 0.57 & 0.43 \\
\hline $10^{4}$ cells $\cdot \mathrm{mL}^{-1}$ & $19.5 \pm 3.4^{\#}$ & $18.7 \pm 3.9^{\#}$ & $10.3 \pm 1.5$ & 0.92 & 1.19 & 0.30 \\
\hline AM \% & $57.3 \pm 6.0^{\#}$ & $61.2 \pm 4.7^{\#}$ & $83.3 \pm 1.8$ & 0.06 & 1.40 & 1.97 \\
\hline $10^{4}$ cells $\cdot \mathrm{mL}^{-1}$ & $11.2 \pm 2.9^{\#}$ & $11.9 \pm 3.2$ & $9.3 \pm 1.4$ & 0.67 & 0.54 & 0.29 \\
\hline Lymphocytes \% & $40.7 \pm 6.1^{\#}$ & $30.6 \pm 4.5^{\#}$ & $14.8 \pm 1.8$ & 0.41 & 1.41 & 1.38 \\
\hline $10^{4}$ cells $\cdot \mathrm{mL}^{-1}$ & $8.0 \pm 1.8^{\#}$ & $5.6 \pm 1.2^{\#}$ & $1.6 \pm 0.36$ & 0.82 & 1.42 & 0.82 \\
\hline PMNs \% & $1.03 \pm 0.39$ & $7.05 \pm 2.03^{\#}$ & $1.21 \pm 0.14$ & 1.65 & 0.68 & 1.38 \\
\hline $10^{4}$ cells $\cdot \mathrm{mL}^{-1}$ & $0.10 \pm 0.02$ & $0.91 \pm 0.19^{\#}$ & $0.13 \pm 0.03$ & 1.65 & 1.09 & 1.53 \\
\hline Eosinophils \% & $0.31 \pm 0.15$ & $0.86 \pm 0.53$ & $0.55 \pm 0.18$ & 0.31 & 0.30 & 0.17 \\
\hline $10^{4}$ cells $\cdot \mathrm{mL}^{-1}$ & $0.05 \pm 0.03$ & $0.19 \pm 0.11^{\#}$ & $0.03 \pm 0.05$ & 0.30 & 0.42 & 0.49 \\
\hline $\mathrm{CD} 4 / \mathrm{CD} 8$ ratio & $4.4 \pm 1.2^{\#}$ & $3.0 \pm 0.5$ & $1.9 \pm 0.3$ & 0.37 & 0.90 & 0.89 \\
\hline
\end{tabular}

Data are presented as mean values \pm SEM. Group 1: patients with an absolute number of polymorphonuclear neutrophils (PMNs) in BALF $\leq 0.2 \times 10^{4}$ cells $\cdot \mathrm{mL}^{-1}$; group 2 : patients with PMNs $>0.2 \times 10^{4}$ cells $\cdot \mathrm{mL}^{-1}$; group 3 : a healthy control group (all nonsmokers). AM: alveolar macrophages. ${ }^{+}$: $\mathrm{p}<0.03$ group 1 versus group 2 ; ${ }^{\sharp}: \mathrm{p}<0.0001$ versus group 3 . 
Table 2. - A summary of the clinical characteristics of patients with sarcoidosis

\begin{tabular}{|c|c|c|c|}
\hline & Group 1 & Group 2 & Cohen's d \\
\hline \multicolumn{4}{|l|}{ Laboratory characteristics } \\
\hline ESR $(0-12) \mathrm{mm} \cdot \mathrm{h}^{-1}$ & $13.9 \pm 3.7$ & $13.3 \pm 3.2$ & 0 \\
\hline SACE $(9-25) U \cdot L^{-1}$ & $25.5 \pm 2.0$ & $26.8 \pm 2.0$ & 0.41 \\
\hline Calcium $(2.10-2.60) \mathrm{mmol} \cdot \mathrm{L}^{-1}$ & $2.45 \pm 0.02$ & $2.40 \pm 0.03$ & 0 \\
\hline Uric acid $(0.20-0.42) \mathrm{mmol} \cdot \mathrm{L}^{-1}$ & $0.37 \pm 0.02$ & $0.35 \pm 0.05$ & 0 \\
\hline C-reactive protein $(2-9) \mu \mathrm{g} \cdot \mathrm{mL}^{-1}$ & $7.8 \pm 1.5$ & $10.9 \pm 2.1$ & 0.44 \\
\hline \multicolumn{4}{|l|}{ Lung function test results } \\
\hline FEV1 \% pred & $97.6 \pm 2.7^{\#}$ & $68.6 \pm 6.1$ & 1.11 \\
\hline FVC $\%$ pred & $113.5 \pm 6.0^{\#}$ & $81.5 \pm 6.1$ & 1.16 \\
\hline$T \mathrm{~L}, \mathrm{CO} \%$ pred & $100.9 \pm 4.2^{\#}$ & $67.8 \pm 7.3$ & 1.09 \\
\hline$P \mathrm{I}, \max (\mathrm{RV}) \mathrm{cmH}_{2} \mathrm{O}$ & $-95.4 \pm 6.8$ & $-83.6 \pm 7.7$ & 0.40 \\
\hline$P \mathrm{E}, \max (\mathrm{TLC}) \mathrm{cmH}_{2} \mathrm{O}$ & $108.0 \pm 10.0$ & $96.2 \pm 8.6$ & 0.26 \\
\hline$P \mathrm{a}, \mathrm{O}_{2} \mathrm{kPa}$ & $12.1 \pm 0.5^{*}$ & $10.3 \pm 0.5$ & 0.88 \\
\hline \multicolumn{4}{|l|}{ Imaging procedures } \\
\hline Radiographic stage 0/I/II/III/IV n & $3 / 5 / 7 / 0 / 0 * * *$ & $0 / 0 / 4 / 6 / 1$ & \\
\hline \multicolumn{4}{|l|}{${ }^{67} \mathrm{Ga}$ scintigraphy scores yes/no n } \\
\hline Lymph nodes, mediastinal/hilar & $8 / 7$ & $5 / 6$ & \\
\hline Lung parenchyma & $3 / 12 * * *$ & $8 / 3$ & \\
\hline Extrathoracic localization & $7 / 8$ & $6 / 5$ & \\
\hline \multicolumn{4}{|l|}{ HRCT scores } \\
\hline Thickening or irregularity of BVB & $0.25 \pm 0.13 * * *$ & $1.90 \pm 0.41$ & 1.77 \\
\hline Enlargement of LN & $1.00 \pm 0.28^{*}$ & $1.80 \pm 0.25$ & 0.45 \\
\hline Septal and nonseptal lines & $0.25 \pm 0.13 * * *$ & $1.30 \pm 0.33$ & 1.02 \\
\hline Intraparenchymal nodules & $0.33 \pm 0.26^{\#}$ & $2.20 \pm 0.33$ & 1.34 \\
\hline Parenchymal consolidation & $0.50 \pm 0.26^{*}$ & $1.30 \pm 0.26$ & 0.68 \\
\hline Total score & $2.50 \pm 0.45^{\#}$ & $8.50 \pm 0.93$ & 1.69 \\
\hline \multicolumn{4}{|l|}{ Follow-up } \\
\hline Spontaneous remission yes/no $\mathrm{n}$ & $14 / 1 * * *$ & $4 / 7$ & \\
\hline
\end{tabular}

Data are presented as mean \pm SEM. Reference ranges of laboratory values are shown in parentheses. Group 1: patients with an absolute number of polymorphonuclear neutrophils (PMNs) in bronchoalveolar lavage fluid $\leq 0.2 \times 10^{4}$ cells $\cdot \mathrm{mL}^{-1}$; group 2: patients with PMNs $>0.2 \times 10^{4}$ cells $\cdot \mathrm{mL}^{-1}$ (all nonsmokers). ESR: erythrocyte sedimentation rate; sACE: serum angiotension converting enzyme; FEV1: forced expiratory volume in one second; FVC: forced vital capacity; TL,CO: transfer factor of the lung for carbon monoxide; PI,max (RV): maximal inspiratory mouth pressure at residual volume; $P$ E, max (TLC): maximal expiratory mouth pressure at total lung capacity; $\mathrm{Pa}_{\mathrm{a}} \mathrm{O}_{2}$ : arterial oxygen tension; HRCT: high-resolution computed tomography; BVB: bronchovascular bundle; LN: lymph nodes. *: $\mathrm{p}<0.05 ; * * * \mathrm{p}<0.001 ;{ }^{\#}: \mathrm{p}<0.0001$, group 1 versus group 2.

The three other patients did not respond at all to the initiated corticosteroid treatment. In two cases methotrexate was started once a week orally, whilst in the third case cyclophosphamide was considered. These three patients, having the most severe sarcoidosis, all appeared to have an absolute number of PMNs in BALF above $1 \times 10^{4}$ cells. $\mathrm{mL}^{-1}$. The final effect of the immunosuppressive agents could not be evaluated.

\section{Course of the disease of the studied sarcoidosis patients}

With respect to the course of the disease, the sarcoidosis patients were divided into three groups: those who recovered spontaneously (group $\mathrm{A} ; \mathrm{n}=18$ ), those who responded to corticosteroid treatment (group $\mathrm{B} ; \mathrm{n}=5$ ) and those who deteriorated (group $\mathrm{C} ; \mathrm{n}=3$ ); (table 3 ). Only the $\mathrm{ab}-$ solute number of PMNs in BALF differed significantly between group $\mathrm{C}$ (Cohen's d 5.71) versus group A as well as group B (Cohen's d 2.26). Almost all the patients in groups $\mathrm{A}$ and $\mathrm{B}$ demonstrated an absolute PMN value $<0.92 \times 10^{4}$ cells $\cdot \mathrm{mL}^{-1}$. The only exception appeared to have a PMN value of $1.40 \times 10^{4}$ cells $\cdot \mathrm{mL}^{-1}$. The patients in group $C$ had an absolute PMN value of $\geq 1.22 \times 10^{4}$ cells $\cdot \mathrm{mL}^{-1}$. The percentage PMNs differed between group $\mathrm{A}$ and group $\mathrm{C}$ (Cohen's d 2.43). The FEV1 differed between group A versus group B (Cohen's d 2.10) and group C (Cohen's d 3.43). The TL,CO differed between group A versus group B (Cohen's d 1.47) and group C (Cohen's d 2.83). The visual HRCT subscore thickening or irregularity of the BVB differed between group A versus group B (Cohen's d 1.78) and group C (Cohen's d $2.95)$. In contrast, no such differences were found in the lymphocyte count or any other cell type present in BALF nor in the presented extrapulmonary symptoms such as erythema nodosum. When looking at the frequency contribution of the radiographic stage of the three recovery groups, it appeared that in group A three patients had radiographic stage 0 , five had stage I, eight had stage II, and two had stage III. In group B, there were two patients with stage II and two with stage III. Finally, of the patients in group C one had stage II, one had stage III, and one had stage IV (Chi-squared $(8)=13.3, p=0.01$ ).

\section{Discussion}

The present study showed that patients suffering from sarcoidosis (with a more advanced, chronic disease course, functional impairment, poor response to corticosteroid treatment and persisting abnormal chest radiographs) demonstrated a higher number of PMNs, but not a different number of lymphocytes in BALF compared to those who recovered spontaneously. These findings point out the 
Table 3. - Summary of the clinical characteristics of sarcoidosis patients with respect to the course of the disease

\begin{tabular}{|c|c|c|c|c|c|c|}
\hline & \multirow{2}{*}{$\begin{array}{c}\text { Group A } \\
n=18\end{array}$} & \multirow{2}{*}{$\underset{n=5}{\text { Group }} B$} & \multirow{2}{*}{$\underset{n=3}{\text { Group } C}$} & \multicolumn{3}{|c|}{ Cohen's d } \\
\hline & & & & Group A vs B & Group A vs C & Group B vs C \\
\hline \multicolumn{7}{|l|}{ Laboratory characteristics } \\
\hline sACE $(9-25) \mathrm{U} \cdot \mathrm{L}^{-1}$ & $26.5 \pm 1.86$ & $25.8 \pm 2.06$ & $24.0 \pm 2.89$ & 0.10 & 0.33 & 0.32 \\
\hline C-reactive protein $(2-9) \mu \mathrm{g} \cdot \mathrm{mL}^{-1}$ & $8.86 \pm 1.61$ & $8.33 \pm 4.10$ & $10.67 \pm 2.40$ & 0.09 & 0.32 & 0.40 \\
\hline \multicolumn{7}{|l|}{ Lung function test results } \\
\hline FEV1 \% pred & $96.3 \pm 2.4$ & $67.0 \pm 10.3^{* *}$ & $59.7 \pm 7.8 * *$ & 2.10 & 3.43 & 0.12 \\
\hline$T \mathrm{~L}, \mathrm{CO} \%$ pred & $98.2 \pm 4.5$ & $70.8 \pm 7.5^{* *}$ & $45.7 \pm 8.5 * *$ & 1.47 & 2.83 & 1.57 \\
\hline$P \mathrm{I}, \max (\mathrm{RV}) \mathrm{cmH}_{2} \mathrm{O}$ & $-97.1 \pm 6.0$ & $-78.7 \pm 7.5$ & $-67.3 \pm 7.0$ & 1.81 & 1.31 & 0.90 \\
\hline \multicolumn{7}{|l|}{ Imaging procedures $\mathrm{HRCT}$ scores } \\
\hline BVB & $0.40 \pm 0.21$ & $2.00 \pm 0.58^{* *}$ & $2.68 \pm 0.33^{* *}$ & 1.78 & 2.95 & 1.68 \\
\hline LN & $1.40 \pm 0.25$ & $0.75 \pm 0.48$ & $2.01 \pm 0.00$ & 0.65 & 0.66 & 1.65 \\
\hline LS & $0.53 \pm 0.19$ & $1.02 \pm 0.58$ & $1.33 \pm 0.88$ & 0.57 & 0.90 & 0.25 \\
\hline ND & $1.03 \pm 0.35$ & $1.25 \pm 0.75$ & $2.02 \pm 0.58$ & 0.18 & 0.75 & 0.57 \\
\hline $\mathrm{PC}$ & $0.53 \pm 0.22$ & $1.75 \pm 0.48$ & $1.33 \pm 0.33$ & 1.44 & 1.04 & 0.49 \\
\hline Total score & $4.02 \pm 0.88$ & $6.80 \pm 1.59$ & $9.28 \pm 0.88$ & 0.81 & 1.68 & 0.85 \\
\hline \multicolumn{7}{|l|}{ BALF analysis results } \\
\hline Lymphocytes \% & $40.4 \pm 4.98$ & $19.7 \pm 4.16$ & $40.2 \pm 12.94$ & 1.08 & 0.01 & 1.32 \\
\hline $10^{4} \mathrm{cell} \cdot \mathrm{mL}^{-1}$ & $7.77 \pm 1.61$ & $3.41 \pm 1.27$ & $8.39 \pm 4.02$ & 0.71 & 0.09 & 1.03 \\
\hline PMNs \% & $1.58 \pm 0.47$ & $5.42 \pm 2.18$ & $12.40 \pm 6.18^{* *}$ & 1.33 & 2.43 & 0.92 \\
\hline $10^{4}$ cells $\cdot \mathrm{mL}^{-1}$ & $0.20 \pm 0.05$ & $0.58 \pm 0.24^{\#}$ & $1.71 \pm 0.32 * *$ & 1.30 & 5.71 & 2.26 \\
\hline
\end{tabular}

Data are presented as mean \pm SEM. Reference ranges of laboratory values in parentheses. Group A: patients who recovered spontaneously; group B: patients who responded to corticosteroid treatment; group C: those patients who deteriorated. LS: septal and nonseptal lines; ND: intraparenchymal nodules; PC: parenchymal consolidation; BALF: bronchoalveolar lavage fluid; PMNs: polymorphonuclear neutrophils. For other definitions see footnote to table 2 . ${ }^{* *}: \mathrm{p}<0.001$ versus group $\mathrm{A} ;{ }^{\#}: \mathrm{p}<0.001$ versus group $\mathrm{C}$.

potential practical value of cellular BALF analysis in patients suffering from sarcoidosis in assessing the prognosis of their disease, in addition to the diagnostic value.

There is considerable incongruity among the clinical, radiographic, physiological and immunological findings used in predicting the course and prognosis of the granulomatous process in sarcoidosis [1, 14, 16-19]. The intensity of the alveolitis was thought to correlate with the course of the disease [20]. Many patients with an acute onset and good prognosis were found to have a lymphocytosis and high CD4/CD8 ratio in the BALF. Similar to other studies $[21,22]$, this and previous studies [4, 5] demonstrated a similar discordance between the intensity of the inflammatory process, indicated by lymphocytosis, and the course of the disease. In contrast, a negative relationship between the pretreatment absolute number of PMNs in BALF and remission of the disease was found. It is realized that the results of this study should be interpreted with caution due to the rather limited sample size of the studied sarcoidosis patient population. However, the results are in agreement with the findings of Rотн et al. [23] and Lin et al. [24] who also demonstrated that abnormal neutrophil counts in BALF were associated with a poor prognosis in sarcoidosis.

Mostly, in IPF or cryptogenic fibrosing alveolitis (CFA) and in collagen vascular diseases, a lymphocytosis in BALF indicated a moderate-to-severe alveolar inflammation and a good response to treatment with corticosteroids $[7,8]$. In contrast, a neutrophilic and eosinophilic alveolitis was associated with a poor clinical response. As in many other diffuse interstitial lung disorders a great deal of uncertainty remains about the appropriate way to treat sarcoidosis, compounded by the lack of knowledge of how to predict the natural course of the untreated disease $[1,24,25]$. In most cases, pulmonary involvement stabilizes or clears in $>80 \%$ of affected patients. In the present study, all but one $(85.7 \%)$ of the cases of group 1 with a normal number of PMNs in BALF demonstrated clinical improvement at the six months assessment, suggesting that the degree of illness was reversible. BAUGHMAN et al. [26] demonstrated that patients who die from respiratory failure due to their sarcoidosis had fibrosis shown on chest radiography and a reduced vital capacity, usually $<1.5 \mathrm{~L}$. In the present study, the radiographic stage as well as the visual HRCT score were found to be related with the course of the disease. Moreover, the three patients for whom lung transplantation was considered, demonstrated more or less severe fibrotic signs and high numbers of PMNs in BALF.

SACE levels and other markers of cell activation sarcoidosis $[2,19]$ as well as ${ }^{67} \mathrm{Ga}$ scans in general have a poor predictive value $[25,27]$. In the present study, no difference was found between the two sarcoidosis subgroups and clinical recovery with respect to the sACE level. Similar to others [17-19], this study did not find that the ${ }^{67} \mathrm{Ga}$ scintigraphy, findings were superior to the HRCT findings, but appeared to be useful to assess extrathoracic localizations of sarcoidosis [14]. Moreover, this study, in agreement with REMY-JARDIN et al. [28], found a correlation of the HRCT appearance with the FEV1, TL,CO, PI,max as well as the absolute number of PMNs in $\mathrm{BALF}$, whereas the ${ }^{67} \mathrm{Ga}$ uptake only appeared to be related to the FEV1 (data not shown). With respect to lung function, it was found that cases with a high number of PMNs in BALF demonstrated significantly more impairment compared to sarcoidosis patients with a normal absolute number of PMNs in BALF. KARETZKY and McDonough [29] demonstrated that the magnitude of functional impairment varied widely from apparent histopathological involvement as reflected by a chest radiograph and lung volumes. They found a wide spectrum of tissue inflammation and organ dysfunction between and 
within each radiographic stage. Moreover, their results indicated that a routine chest radiograph provides a very limited estimate of function for any given individual and that a $T \mathrm{~L}, \mathrm{CO}$ of $<55 \%$ was the most sensitive indicator at rest for exercise limitation. In the present study, the FEV1 and TL,CO allowed a distinction between patients who recovered spontaneously and those patients who needed treatment and/or deteriorated. The radiographic stage did not seem to be a potential predictor of disease progression. However, the absolute number of PMNs appeared to be a better potential predictor because this parameter differed significantly between those patients who recovered spontaneously (group A) and those who needed treatment (group B), and in addition, between group B and those who deteriorated (group C).

Sarcoidosis is often acute and self-limiting, but may also have a chronic pattern, waxing and waning over a long period [1]. It is tempting to speculate that the neutrophil component of the inflammation, including mediators such as collagenase [30], toxic oxidant radicals and proteases, also has the potential to contribute to alveolar wall injury in sarcoidosis [23, 24]. In this context, although more data supporting the importance of the neutrophil in the pathogenesis of sarcoidosis are really needed, it is reasonable to suggest that suppression of the neutrophil component of the inflammation of sarcoidosis should also be considered in the treatment decisions. CAR et al. [31] demonstrated significantly elevated interleukin- 8 levels in BALF of sarcoidosis patients and IPF patients. For interleukin- 8 a role has been suggested in the attraction of neutrophils to inflamed tissues.

In conclusion, an increase of the polymorphonuclear neutrophil count in bronchoalveolar lavage fluid obtained from sarcoidosis patients appeared to be associated with more advanced disease. This result highlights that polymorphonuclear neutrophils, but not lymphocytes, may play a crucial role in the outcome of sarcoidosis and evolution of the inflammatory process toward pulmonary fibrosis. Therefore, cellular bronchoalveolar lavage fluid analysis may be of additional practical value in predicting the course of the disease in an individual patient. However, the exact role of polymorphonuclear neutrophils in the pathogenesis and prognosis of patients suffering from sarcoidosis needs further investigation to elucidate the many remaining questions, especially whether they could be therapeutic targets.

\footnotetext{
Acknowledgements. The authors would like to thank H. Voets for her great help in collecting the data, and M. Elfferich for her advice during the preparation of this manuscript.
}

\section{References}

1. Sharma OP, Alam S. Diagnosis, pathogenesis and treatment of sarcoidosis. Curr Opin Pulm Med 1995; 1: 392400.

2. Müller-Quernheim J. The cytokine network in sarcoidosis. Eur Cytokine Netw 1996; 7: 13-26.

3. Newman LS, Rose CS, Maier LA. Sarcoidosis. $N$ Engl J Med 1997; 336: 1224-1234.

4. du Bois RM, Kirby M, Balbi B, Saltini C, Crystal RG. Tlymphocytes that accumulate in the lung in sarcoidosis have evidence of recent stimulation of the T-cell antigen receptor. Am Rev Respir Dis 1992; 45: 1205-1211.

5. Drent M, van Velzen-Blad H, Diamant M, Hoogsteden HC, van den Bosch JMM. Relationship between disease presentation of sarcoidosis and $\mathrm{T}$ lymphocyte profile: a study in bronchoalveolar lavage fluid. Chest 1993; 104: 795-800.

6. Drent M, Grutters JC, Mulder PGH, van Velzen-Blad H, Wouters EFM, van den Bosch JMM. Different imbalance of TH1 and TH2-like activity in sarcoidosis and extrinsic allergic alveolitis reflected by the cellular bronchoalveolar lavage fluid profile. Sarcoidosis Vasc Diffuse Lung Dis 1997; 14: 31-38.

7. The BAL Cooperative Group Steering Committee. Bronchoalveolar lavage constituents in healthy individuals, idiopathic pulmonary fibrosis, and selected comparison groups. Am Rev Respir Dis 1990; 141: 169-202.

8. Chang-Yeung M, Müller NL. Cryptogenic fibrosing alveolitis. Lancet 1997; 850: 651-656.

9. Drent M, van Nierop MAMF, Gerritsen FA, Wouters EFM, Mulder PGH. Computer program using BALF analysis results as diagnostic tool in interstitial lung diseases. Am J Respir Crit Care Med 1996; 153: 736-741.

10. Wirnsberger RM, Vries de J, Wouters EFM, Drent M. Clinical presentation of sarcoidosis in the Netherlands. An epidemiological study. Neth J Med 1998; 53: 53-60.

11. Quanjer PH, Tammeling GJ, Cotes JE, Pederson OF, Peslin R, Yernault J-C. Lung volumes and forced ventilatory flows. Report working party. Standardization of lung function tests. European Commission for Steel and Coal. Official statement of the European Respiratory Society. Eur Respir J 1993; 6: Suppl. 16, 5s-40s.

12. Drent M, Wirnsberger RM, de Vries J, van Dieijen-Visser MP, Wouters EFM, Schols AMWJ. Association of fatigue with and acute phase response in sarcoidosis. Eur Respir J 1999; 13: 718-722.

13. Oberstein A, von Aitzewitz H, Schweden F, MüllerQuernheim J. Non invasive evaluation of the inflammatory activity in sarcoidosis with high-resolution computed tomography. Sarcoidosis Vasc Diffuse Lung Dis 1997; 14: 65-72.

14. Liem IH, Drent M, Antevska E, Lamers RJS, Heidendal GAK. Intensive muscle uptake of Gallium-67 in a patient with sarcoidosis. J Nuclear Med 1998; 39: 1605-1607.

15. Cohen J. Statistical Power Anaysis for the Behavioral Sciences. 2nd Edn. Hillsdale, NJ, Erlbaum, 1988.

16. Staton GW, Gilman MJ, Pine JR, Fajman WA, Check IJ. Comparison of clinical parameters, bronchoalveolar lavage, gallium-67 lung uptake, and serum angiotensin converting enzyme in assessing the activity of sarcoidosis. Sarcoidosis 1986; 3: 10-18.

17. Turner-Warwick M, McAllister W, Lawrence R, Britton A, Hasiam PL. Corticosteroid, treatment in pulmonary sarcoidosis: do serial lavage lymphocyte counts, serum angiotensin converting enzyme measurements and gallium-67 scans help management? Thorax 1986; 41: 903913.

18. Müller-Quernheim J, Pfeiffer S, Strausz J, Ferlinz R. Correlation of clinical and immunologic parameters of the inflammatory activity of pulmonary sarcoidosis. Am Rev Respir Dis 1991; 144: 1322-1329.

19. Gottlieb J, Israel H, Steiner R, Triolo J, Patrick H. Outcome of sarcoidosis. Chest 1997; 111: 623-631.

20. Ward K, O'Conner C, Odlum C, Fitzgerald XM. Prognostic value of bronchoalveolar lavage in sarcoidosis: the critical influence of disease presentation. Thorax 1989; 44: 6-12. 
21. Winterbauer RH, Lammert J, Selland M, Rae Wu, Corley $\mathrm{D}$, Springmeyer SC. Bronchoalveolar lavage cell populations in the diagnosis of sarcoidosis. Chest 1993; 104: 352-361.

22. Kantrow SP, Meyer KC, Kidd P, Raghu G. The CD4/CD8 ratio in BAL fluid is highly variable in sarcoidosis. Eur Respir J 1997; 10: 2716-2721.

23. Roth C, Huchson GJ, Arnoux A, Staaslan-Lequern G, Marsac JH, Chretien J. Bronchoalveolar cells in advanced pulmonary sarcoidosis. Am Rev Respir Dis 1981: 124: 912.

24. Lin YH, Haslam PL, Turner-Warwick M. Chronic pulmonary sarcoidosis: relationship between lung lavage cell counts, chest radiograph, and results of standard lung function tests. Thorax 1985; 40: 501-507.

25. Rizzato G, Montemurro L, Colombo P. The late follow-up of chronic sarcoid patients previously treated with corticosteroids. Sarcoidosis Vasc Diffuse Lung Dis 1998; 15: 52-58.

26. Baughman RP, Winget DB, Bowen E, Lower EE.
Predicting respiratory failure in sarcoidosis patients. Sarcoidosis Vasc Diffuse Lung Dis 1997; 14: 154-158.

27. Israel HL, Albertine KH, Park CH, Patrick H. Wholebody gallium 67 scans. Role in diagnosis of sarcoidosis. Am Rev Respir Dis 1991; 144: 1182-1186.

28. Remy-Jardin M, Giraud F, Remy J, et al. Pulmonary sarcoidosis: role of CT in the evaluation of disease activity and functional impairment and in prognosis assessment. Radiology 1994; 191: 675-680.

29. Karetzky M, McDonough M. Exercise and resting pulmonary function in sarcoidosis. Sarcoidosis 1996; 13: 43-49.

30. Ward K, O'Conner M, Odlum C, Power C, Fitzgerald MX. Pulmonary disease progress in sarcoid patients with and without bronchoalveolar lavage collagenase. $\mathrm{Am} \mathrm{Rev}$ Respir Dis 1990; 142: 636-641.

31. Car BD, Meloni F, Luisetti M, et al. Elevated IL-8 and MCP-1 in the bronchoalveolar lavage fluid of patients with idiopathic pulmonary fibrosis and pulmonary sarcoidosis. Am J Respir Crit Care Med 1994; 149: 655-659. 